\title{
DYNAMIC NON-LINEAR ANALYSIS OF A CRACKED BLADE
}

\section{Mykola Kulyk $^{1}$, Olexiy Kucher ${ }^{2}$, Vsevolod Kharyton ${ }^{3}$, Jean-Pierre Laine ${ }^{4}$, Fabrice Thouverez}

\author{
${ }^{1,2}$ National Aviation University, 1 Cosmonavta Komarova Ave., Kiev 01058, Ukraine \\ ${ }^{3,4,5}$ Ecole Centrale de Lyon, Equippe D2S, 36. Guy de Collongue Ave., Ecully 69130, France \\ E-mails: ${ }^{1}$ kafad@nau.edu.ua, ${ }^{2}$ kucher@nau.edu.ua, ${ }^{3}$ vsevolod.kharyton@gmail.com, ${ }^{4}$ jean-pierre.laine@ec-lyon.fr, \\ 5 fabrice.thouverez@ec-lyon.fr
}

Received 19 June 2008; accepted 14 August 2008

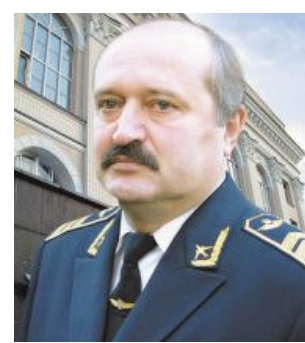

Mykola KULYK, Prof Dr Sci Eng

Education: Kiev Institute of Civil Aviation Engineers, 1976. 1993 - Doctor of Science (Engineering) Affiliations and functions: 1997 - head of the Air Engines Department.

Honours, awards: Honored figure of Science and Engineering of Ukraine, Winner of the State Price of Ukraine in the area of science and technology.

Present position: rector of National Aviation University, Ukraine.

Research interests: automatic systems of aircraft engines technical conditions.

Publlications: over 200 scientific papers.

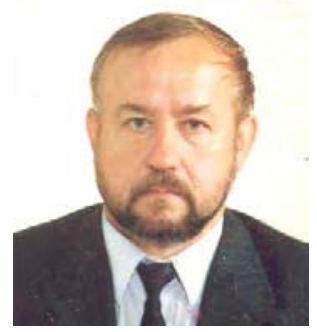

Olexiy KUCHER, Prof Dr Habil

Present position: professor of Aeroengines Department, National Aviation University. Research interests: reliability, strength and health monitoring of aviation technique.

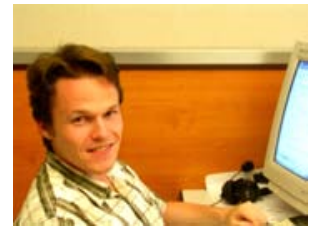

Vsevolod KHARYTON, post-graduate student

Present position: post-graduate student in collaboration between National Aviation University and Ecole Centrale de Lyon.

Research interests: vibration analysis of cracked structures, non-contact methods application and development of cracked structures identification.

*) corresponding author

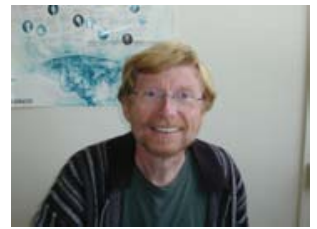

Jean-Pierre LAINE, Prof Dr Habil

Present position: professor of MSGSM department, Ecole Centrale de Lyon.

Research interests: dynamics of complex structures, contact and stability analyses.

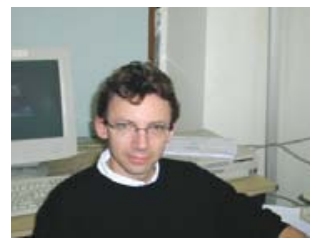

Fabrice THOUVEREZ, Prof Dr Habil

Present position: head of MSGMGC department, professor of Ecole Centrale de Lyon.

Research interests: non-linear analysis, analysis of uncertain systems. 


\begin{abstract}
A cracked blade non-linear dynamic analysis was performed, taking into account contact interaction between crack sides. The contact-induced non-linear problem was solved by using the harmonic balance method. Accuracy and computational efficiency are demonstrated by comparing the results with the time integration of the system's motion equation Problem size reduction was performed using system fixed-interface method. They suppose that a crack forms an interface between two sub-structures and use a relative degree of freedom to describe the motion of crack sides. The influence of centrifugal forces was investigated in order to understand the necessity of problem non-linear formulation depending on crack location and frequency of rotation.
\end{abstract}

Keywords: cracked blade, contact, harmonic balance method, frequency response function, eigenfrequency.

\section{Introduction}

In a majority of the works in the field of cracked blade dynamic analysis, the presence of a crack is simulated by a reduction in the stiffness of a structure leading to a reduction in natural frequencies and correspondingly a shift in resonances at frequency response function construction. The crack models used in these analyses are divided into two categories, supposing stiffness to be constant or changing with excitation frequency and applied external loading:

- $\quad$ open crack models-linear statement, stiffness is maintained constant during analysis;

- opening and closing or breathing crack modelsnon-linear statement, stiffness is changed depending on external loading conditions (Laine et al. 2006, Cheng et al. 1999).

As it was said, generally, open crack models are used because of their simplicity and because they provide important diagnostic signa such as natural frequency decrease. Then it can be used for the identification of the presence of cracks in the blade, which is a very challenging task and is in the scope of both industry and scientific circles.

\section{Non-linear cracked blade model}

In our work, we will deal with a three-dimensional cracked blade model with the following geometrical and material properties:

- thickness-4 mm;

- height-80 mm;

- wideness-30 $\mathrm{mm}$;

- twisting angle- $30^{\circ}$;

- Young's modulus-2e11 Pa,

- Poisson's ratio-0.3

- material density- $7.8 \mathrm{e} 3 \mathrm{~kg} / \mathrm{m}^{3}$;

- external force amplitude-0.2N.

A finite-elements model of a cracked blade (fig. $1 b$ ) was created in order to extract mass and stiffness matrices for their following utilization in dynamic analysis. Application of external excitation forces is shown in figure $1 b$. Forces are applied at points of the blade tip: at the leading and trailing edges.

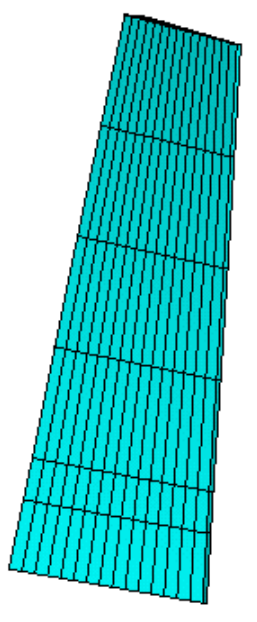

a

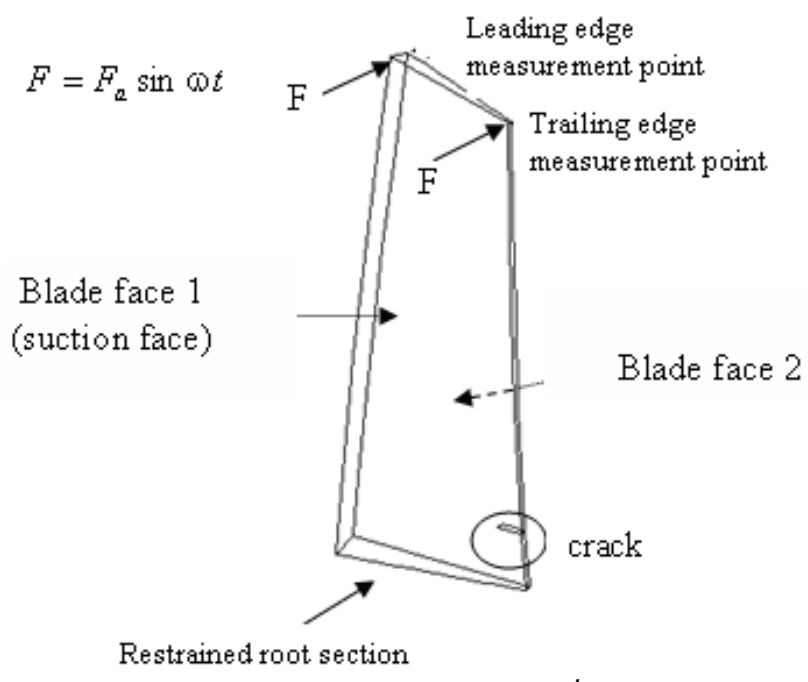

Fig 1. $a$-cracked blade finite-elements model, $b$-cracked blade model subjected to dynamic response analysis

Since excitation period does not always coincide with the response of the crack, the last approach seems to be more practical to use.

In most cases, analytical solutions of such dynamical systems are practically impossible to obtain. Thus, some numerical techniques must be applied. Firstly, systems are discretized as a set of non-linear ordinary differential equations with high dimension. Then traditional direct time integration methods are applied. However, this process is extremely time-consuming. In order to overcome this problem, the harmonic balance method is widely used (Chengwu et al. 2007, Liu et al. 2006, Von Groll et al. 2001). Now, we present in a short form the application of the harmonic balance method. In the nonlinear case, the equation of system motion is expressed by: 


$$
\mathrm{Mu}+\mathrm{C}_{\xi} \dot{\mathrm{u}}+\mathrm{Ku}+\mathrm{F}_{\mathrm{nl}}(\mathrm{u})=\mathrm{F}(\mathrm{t}),
$$

where $\mathrm{M}$ - mass matrix, $\mathrm{K}$ - stiffness matrix, $\mathrm{C}_{\zeta}-$ damping matrix, $\mathrm{u}-$ displacements vector, $\mathrm{F}_{n l}$ - nonlinear force vector, $\mathrm{F}$ - external excitation time-varying periodic force vector. The damping matrix is calculated on the base of the structural damping ratio $\xi$ and stiffness matrix as $C_{\zeta}=\xi K$

Then we are searching for the $u(t)$ in the form of the truncated trigonometric series of $k=1, \ldots, N$ harmonics:

$$
u(t)=a_{0}+\sum_{k=1}^{N} a_{k} \cos k \omega t+\sum_{k=1}^{N} b_{k} \sin k \omega t
$$

where $a_{0}, a_{k}, b_{k}-$ Fourier series coefficients, $\omega-$ excitation frequency.

If we put equation (2) to (1) the last would be changed to:

$$
\mathrm{Au \tilde {u }}+\mathrm{b}(\tilde{\mathrm{u}})=\mathrm{C}
$$

where A is diagonally symmetric in the block matrix:

$$
\begin{aligned}
\mathrm{A} & =\left[\begin{array}{cccc}
\mathrm{L}_{0} & 0 & \ldots & 0 \\
0 & \mathrm{~L}_{1} & \ldots & 0 \\
\ldots & \ldots & \ldots & \ldots \\
0 & 0 & \ldots & \mathrm{L}_{N}
\end{array}\right]_{N_{d o f}(2 k+1) \times N_{d o f}(2 k+1)} ; \\
\mathrm{L}_{0} & =\mathrm{K} ; \mathrm{L}_{\mathrm{k}}=\left[\begin{array}{cc}
\mathrm{K}-(k \omega)^{2} \mathrm{M} & k \omega \mathrm{C}_{\xi} \\
-k \omega \mathrm{C}_{\xi} & \mathrm{K}-(k \omega)^{2} \mathrm{M}
\end{array}\right] .
\end{aligned}
$$

where $\mathrm{b}$ - non-linear member, $\mathrm{C}$ - external excitation force vector and $\tilde{\mathrm{u}}$ - vector of Fourier series coefficients.

Non-linear solution requires taking into account system non-linearity, in our case non-linear contact force between two nodes. The governing equation (3) represents by itself the system of non-linear equations to which some linear transformation could be applied for implementation of a Newton-type iterative method of

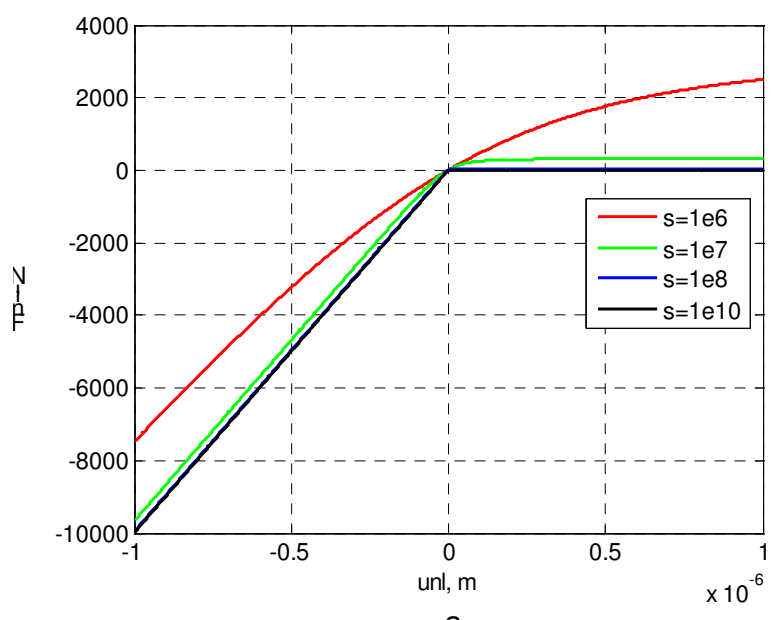

a

Fig 2. Non-linear force smoothing representation: a - at different values of $s$ coefficient and fixed $k_{n l}=10^{10} \mathrm{~N} / \mathrm{m}$, $\mathrm{b}-$ at different values of penalty stiffness $k_{n l}$ and fixed $s=10^{10}$ non-linear algebraic equation systems solution (Chengwu et al. 2007).

The representation of non-linear force is one of the most important tasks in any non-linear analysis and in the harmonic balance method. In our case, we have some non-linear degrees of freedom (relative vertical displacements between contact nodes). To determine the contact force, the Lagrange multipliers or penalty methods could be utilized (Kucher et al. 2007). The easiest way is to use the penalty method to approximate this force by the following expression:

$$
F_{n l}=k_{n l} \cdot\left(\frac{u_{n l}+\left|u_{n l}\right|}{2}\right) \text {, }
$$

where $k_{n l}$ - penalty stiffness and $u_{n l}-$ non-linear DOF displacement. Penalty stiffness value should be chosen to provide minimum penetration in the contact zone.

The disadvantage of the approximation of the nonlinear force when it crosses zero should be mentioned. So then $u_{\mathrm{nl}}=0, \partial F_{n l} / \partial u_{n l} \rightarrow \infty$.

Since calculation of the Jacobean will be theoretically unattainable and in order to avoid this problem, the smoothing function should be applied. In the work of D. Chengwu et al., the tangent function was used for smoothing. We applied it with some modification and have gotten the next expressio:

$$
F_{n l}=\frac{1}{\pi} k_{n l}\left(\arctan \left(s u_{n l}\right)-\frac{\pi}{2}\right) u_{n l},
$$

where $s$ - coefficient, the sufficiently high level of which is required to accurately represent force-displacement relationship smoothing (Fig 2).

And even in such a case some problems with lack of convergence of solutions can appear. This is mostly caused by the level of the penalty stiffness coefficient. In order to overcome these problems, Lagrange multipliers should be used since they allow the use of a sufficiently lower value of penalty stiffness.

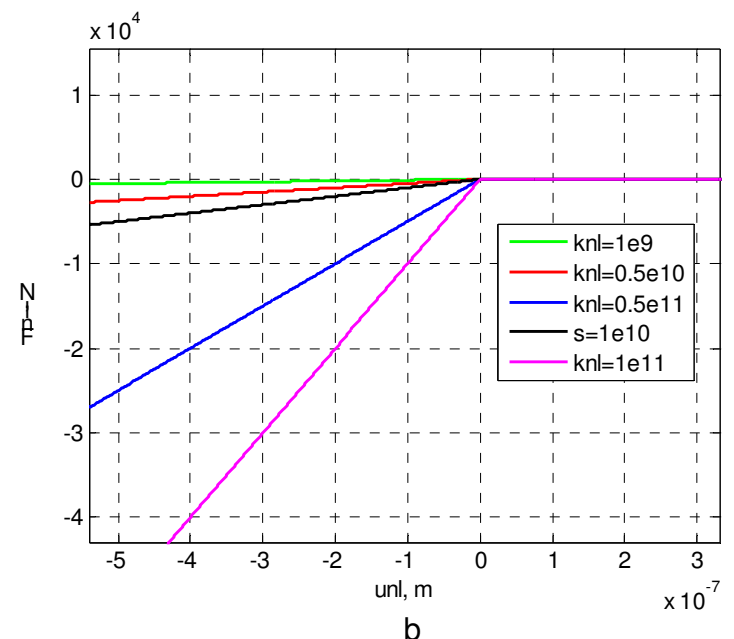

b

\section{.}




\section{System reduction methods}

When doing an analysis of vibration performances of a structure with essentially high accuracy required, we meet the problem of enormous number of DOFs taking part in the solution procedure. For example, the threedimensional model of the blade can have up to 60,000 DOFs, which leads to computational problems in calculation time expenses and memory shortage. The only solution is to reduce the size of the system by using one of the existent reduction methods and reduction methods based on system sub-structuring. The main advantages of such approaches are: partition of the object being analysed on some independent sub-structures, modification of a sub-structure without influencing the rest, and the ability to work with one sub-structure in the case of a number of identical sub-structures (e.g. cyclic symmetry). The most known procedures of system reduction are: the Guyan reduction, fixed interface substructuring method of Craig-Bampton, and free interface sub-structuring method of Mac Neal (Craig et al. 1968).
In figure $3 a$, cracked blade model sub-structuring is presented. The location of the crack forms an interface between the two sub-structures. The lower sub-structure is restrained at the root section and the upper one is free at both ends. To continue with model size reduction, both fixed and free interface methods were implemented with the aim to choose the most applicable.

It should be noted that in this case we do not have classical sub-structuring, because these parts are not fully independent. Some DOF remain shared between the upper and lower sub-structures of the blade. These DOF are relative displacement between contact nodes (Fig 3 b).

With the aim to facilitate calculation processes for each contact pair defined previously as the set of two nodes, one node is selected arbitrarily to be the reference of the displacement observation of the other node. Thus, the relative displacement can be introduced as:

$$
u_{r e l}^{i}=u_{o b s}^{i}-u_{r e f}^{i},
$$

where the subscripts $r e f$ and $o b s$ refer to the reference and the observed nodes respectively and the $i$-th index corresponds to the $i$-th contact pair.

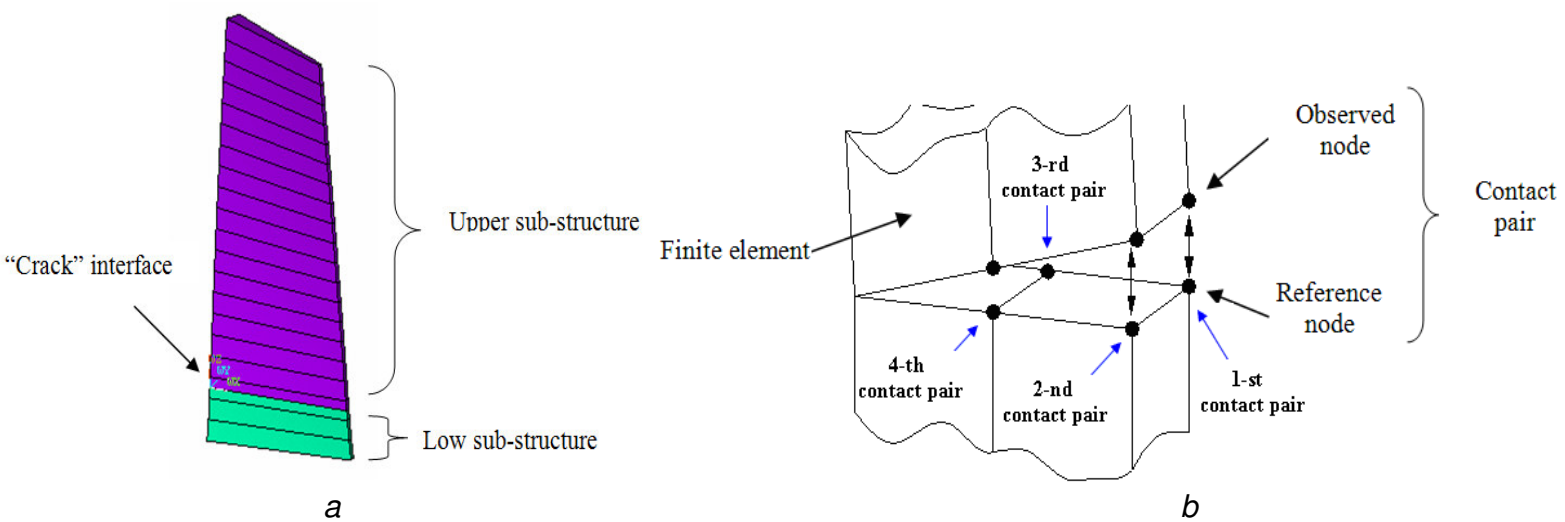

Fig 3. $a$-cracked blade model sub-structuring, $b$ - relative displacements between contact nodes

\section{Non-linear solution by harmonic balance method}

Both non-linear and linear solutions are reconstructed in the time domain by the inverse Fourier transformation and shown for: relative vertical displacement between two coinciding contact nodes (crack point) and excitation force application node horizontal displacement (tip point).

Crack location variants are schematically shown in figure 4, supposing it to be either on the leading or trailing edges or on both edges (symmetric cracks).

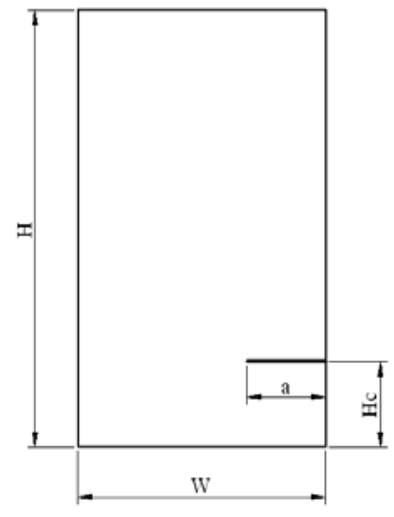

a

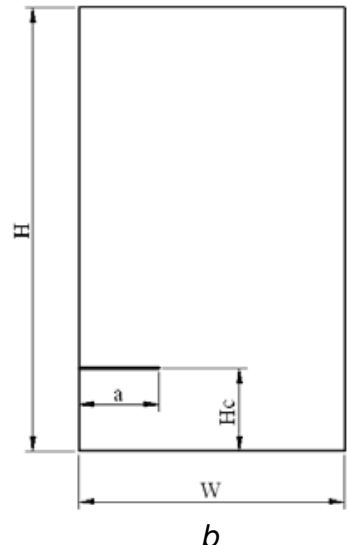

b

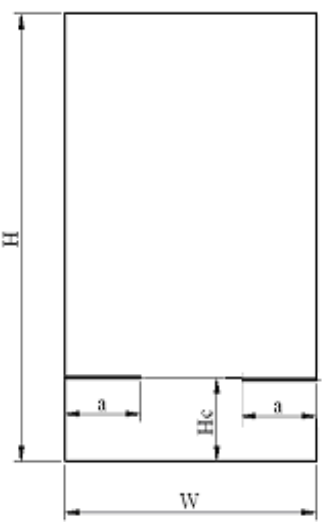

$C$

Fig 4. Crack location variants in the blade $a$ - crack on trailing edge, $b$ - crack on leading edge, $c$ - symmetric cracks 
From the results of contact interaction simulations we can see the representation of the presence of contact force. The set value of penalty stiffness is enough to avoid penetration, and non-linear force approximation (4) allows us to precisely simulate system non-linearity. Five harmonics were retained in this case at excitation frequency, which is close to the first resonance frequency.

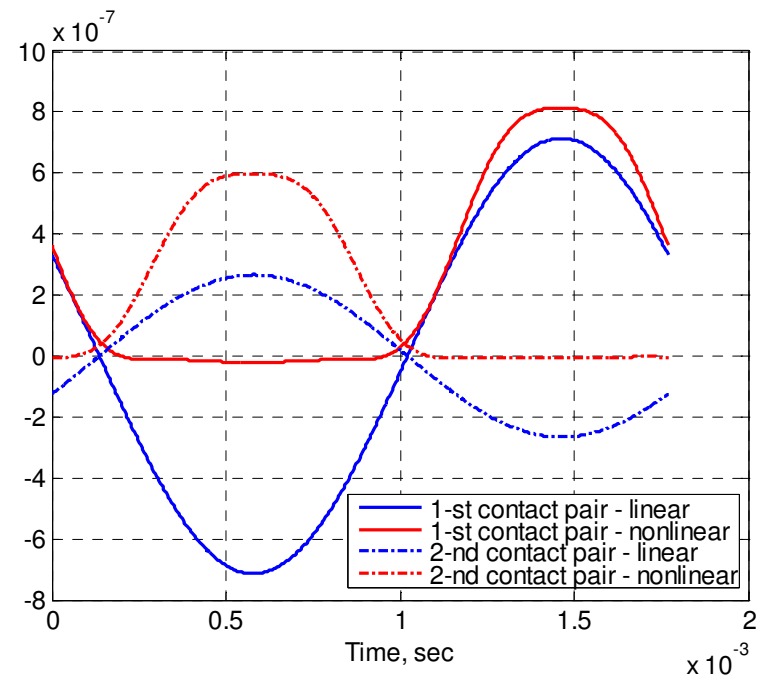

The number of harmonics is very critical at two sides. Firstly, it increases solution time since system size depends on it and, secondly, it is necessary to have their required number to properly describe non-linear displacement change over time.

The solutions of problems for a 2-mm crack located either on the trailing or leading edge are presented in figures 5 and 6.

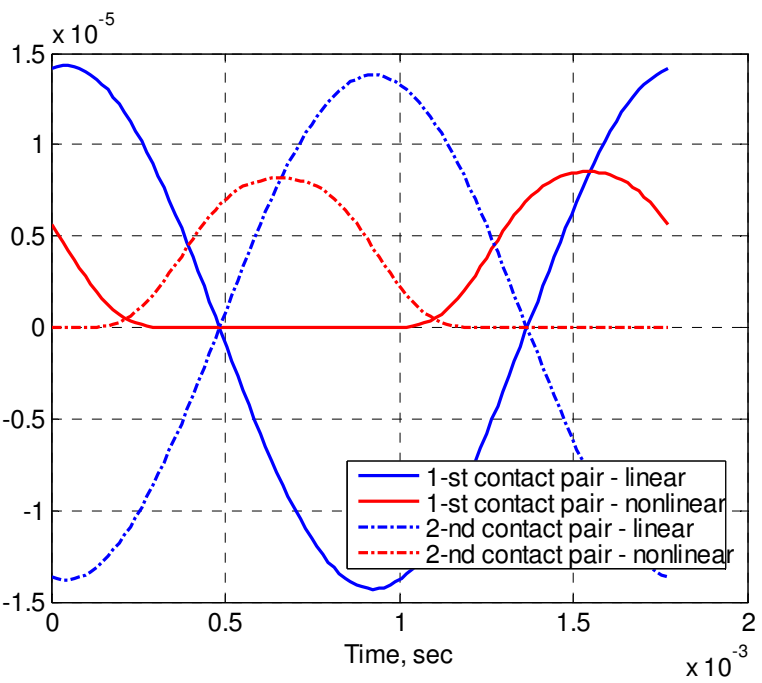

$b$

Fig 5. System response in the time domain at the crack point (crack size $2 \mathrm{~mm}, \omega=3500 \mathrm{rad} / \mathrm{sec}$ ): $a$ - trailing edge crack, $b$ - leading edge crack

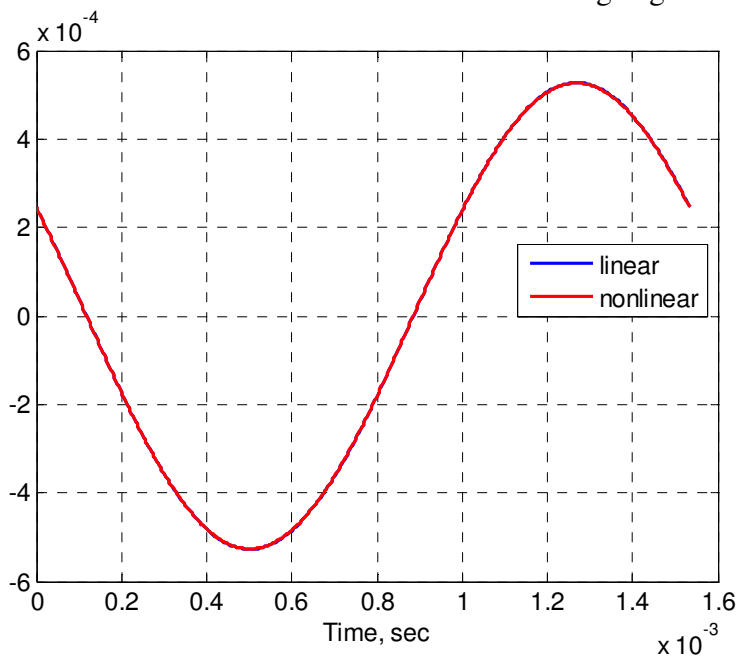

a

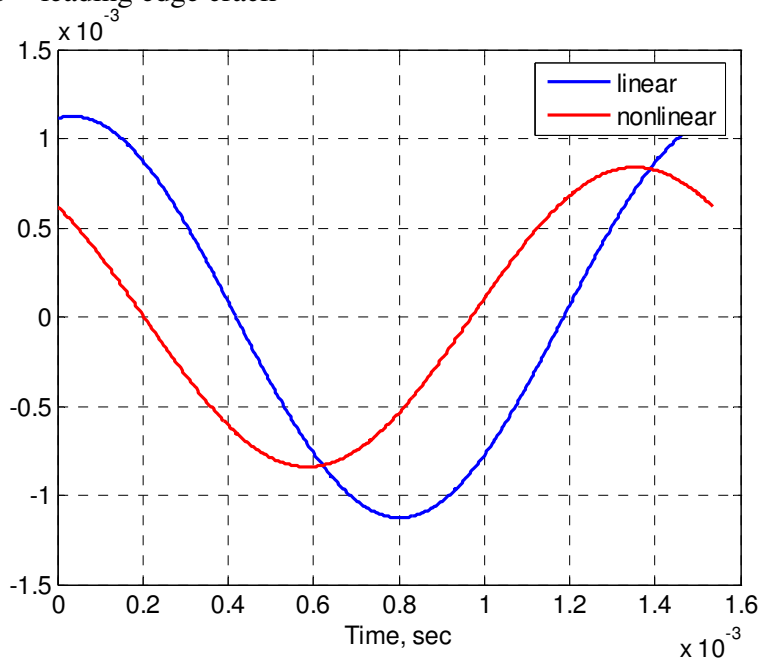

$b$

Fig 6. System response in the time domain at the tip point (crack size $2 \mathrm{~mm}, \omega=3500 \mathrm{rad} / \mathrm{sec}$ ): $a$ - trailing edge crack, $b$ - leading edge crack

From the results of the solution of the cracked blade model in the time domain with an introduced crack of 2 mm length on the trailing edge, it is seen that the influence of presence crack on blade tip response is almost invisible (Fig $5 a$, Fig $6 a$ ). It is also based on the results of modal analysis, which shows the minimum shift in the first eigenmode frequency for such case. For the case in which the crack is located on the leading edge, we have a visually detectable difference between both linear and non-linear solutions (Fig $5 b$, Fig $6 b$ ) because of the higher level of stiffness reduction.

After having considered the smallest crack size, we will go on to examine the influence of a crack on blade dynamic response increasing crack length up to $4 \mathrm{~mm}$ (Figs 7,8). Solutions at the crack and tip points will also be presented for the case of symmetrically located cracks (Figs 9, 10). 

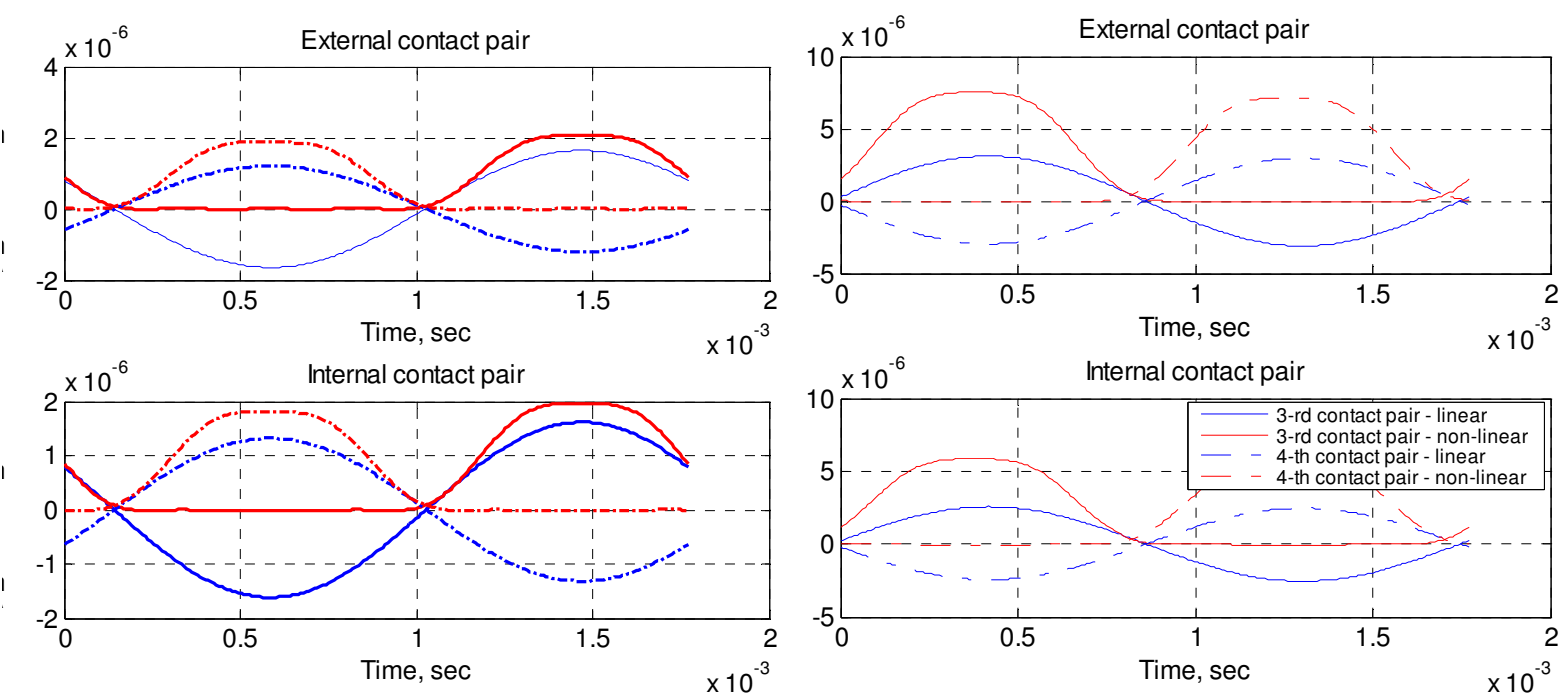

a

$b$

Fig 7. System response in the time domain at crack point (crack size $4 \mathrm{~mm}, \omega=3500 \mathrm{rad} / \mathrm{sec}$ ): $a$ - trailing edge crack, $b$ - leading edge crack

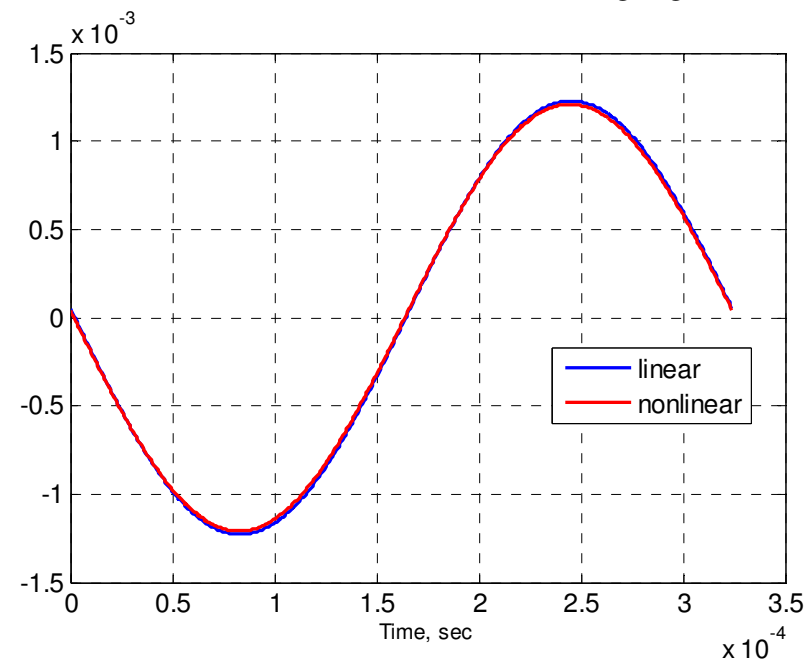

a

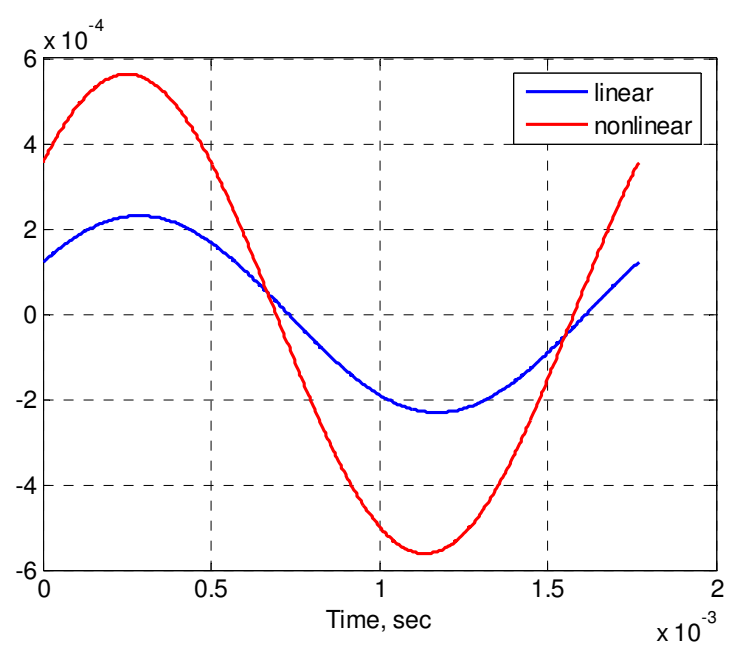

$b$

Fig 8. System response in the time domain at the tip point (crack size $4 \mathrm{~mm}, \omega=3550 \mathrm{rad} / \mathrm{sec}$ ): $a$ - trailing edge crack, $b$ - leading edge crack

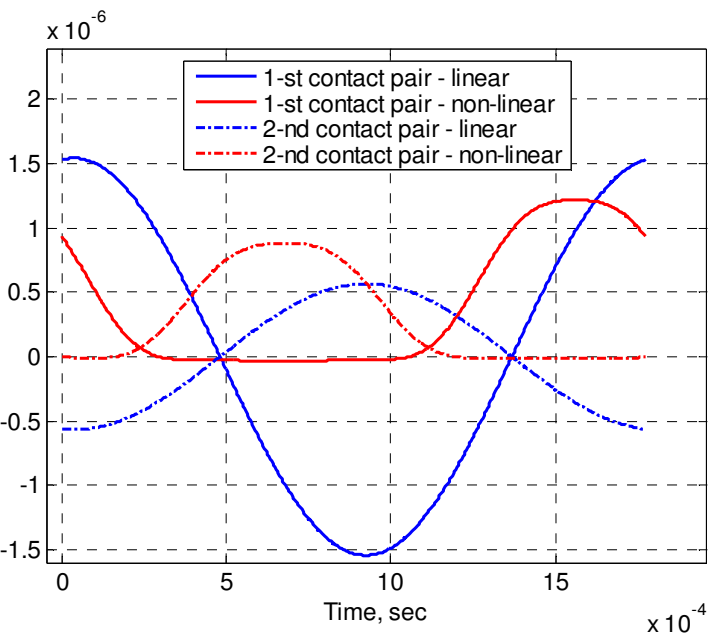

a

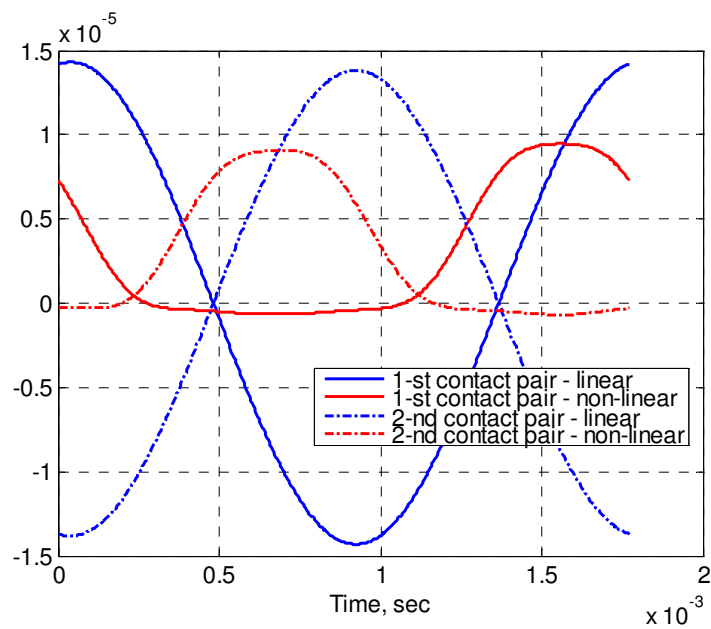

$b$

Fig 9. System response with symmetric cracks in the time domain at the crack point (crack size $2 \mathrm{~mm}, \omega=3550 \mathrm{rad} / \mathrm{sec}$ ): $a$ - crack located on trailing edge, $b$ - crack located on leading edge 

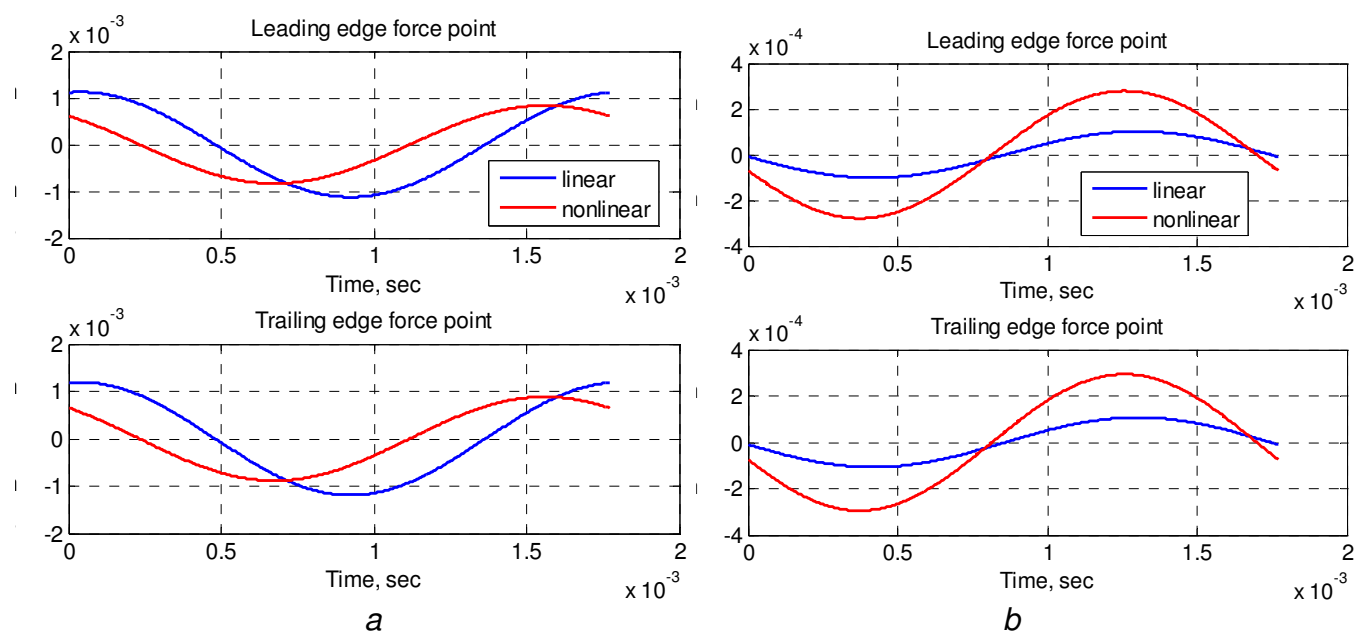

$b$

Fig 10. System response with symmetric cracks in the time domain at the tip point $(\omega=3550 \mathrm{rad} / \mathrm{sec})$ : $a$ - crack size $2 \mathrm{~mm}, \mathrm{~b}$ - crack size $4 \mathrm{~mm}$

In the case of the response in the time domain of the cracked blade with cracks of $4 \mathrm{~mm}$, it is evident that the influence of this size crack is stronger than the 2-mm crack (Figs 7,8). The number of contact pairs through the crack thickness is two (external and internal). This allows more accurate description of the displacements between crack sides in dynamics.

Analyzing the results of the response of the cracked blade with symmetric cracks, we can see that it is mostly influenced by the leading edge crack partition, and even a crack size of $2 \mathrm{~mm}$ becomes more or less visible (Figs 9, 10).

It is also necessary to emphasize that considerable difference between the non-linear model solution and linear model solution for some crack location cases does not reflect the real difference in amplitudes. This generally results from resonance shift because the excitation frequency is not far from the first eigenmode frequency of the linear or non-linear models. The contraposition in the time-history of relative displacements between crack sides for two blade faces is caused by an excited natural mode. In our case, the forces applied at two tip points (figure $1 b$ - leading and trailing edge force points) excites the first bending mode of the blade, and frequency points are located in the range of this mode, inducing such difference.

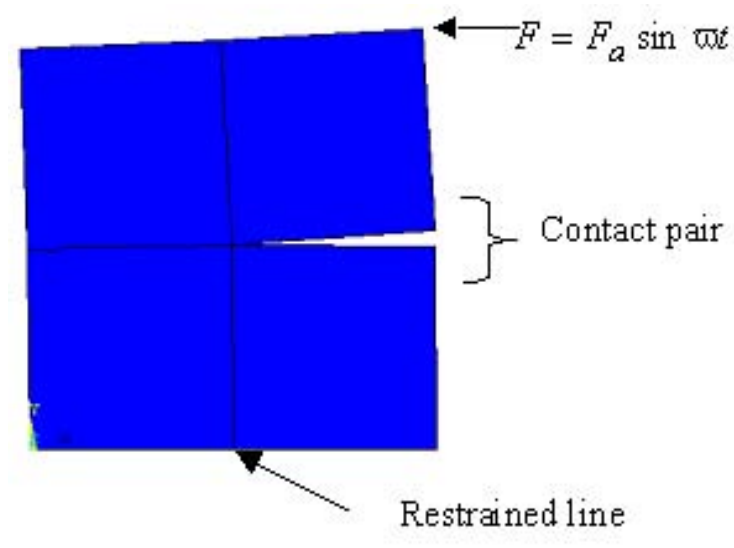

a

\section{Comparison of harmonic balance and direct integration method}

In order to validate the results of the use of the harmonic balance method, they were compared with the results of the direct integration of the system motion equation. For high-dimensional structures, the procedure of finding a solution is very time consuming; it was therefore decided to use a two-dimensional model for such numerical tests.

In our case, the cracked structure is simulated by a flat plate that has dimensions of $0.1 \mathrm{~m} . * 0.1 \mathrm{~m}$. and is restrained at the bottom line (Fig $11 a$ ). The presence of a crack in the structure was simulated by introducing an additional node creating a contact pair. The external load was applied to the top right corner of the plate as the point force with amplitude of $100 \mathrm{~N}$ and excitation frequency of $2100 \mathrm{rad} / \mathrm{sec}$, which is close to the first eigenfrequency of the cracked plate model (2300 $\mathrm{rad} / \mathrm{sec}$ ).

Firstly, cracked blade dynamic response simulations supposing contact between the sides of the crack were fulfilled by the finite elements method (Fig $11 \mathrm{~b}$ ).

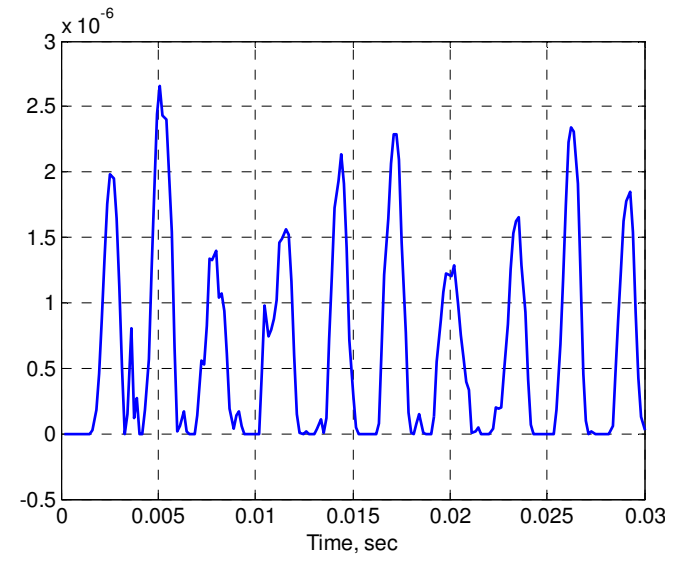

$b$

Fig 11. $a$-Simplified two-dimensional model of the cracked structure, $b$ - Time-history of the relative vertical displacement between crack tips in ANSYS 
Interaction of the cracked interface was modelled by a node-to-node contact element with the use of the penalty method. The normal penalty level was accepted as $10^{11} \mathrm{~N} / \mathrm{m}$. In the work of O. Kucher et al., the solution of the same system was calculated by the direct integration method (Kucher et al. 2007). For the simulation of contact, two methods were applied: the Lagrange multipliers method and the penalty method. In the present work, the Lagrange multipliers method was used for comparison with the harmonic balance method.

It is necessary to point out that, for getting a steadystate solution by direct integration of the equation of system motion, the time interval of the integration should be sufficiently big. It is also important for the time step to be small enough to obtain an accurate solution.

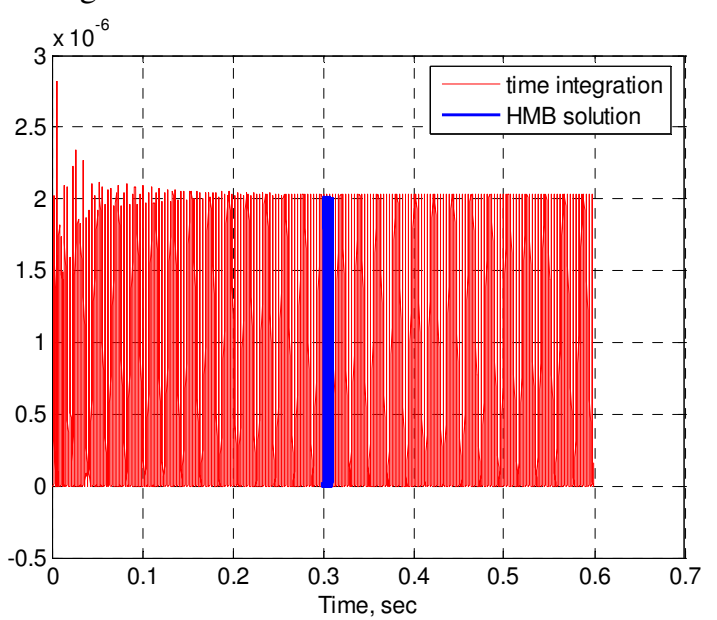

a

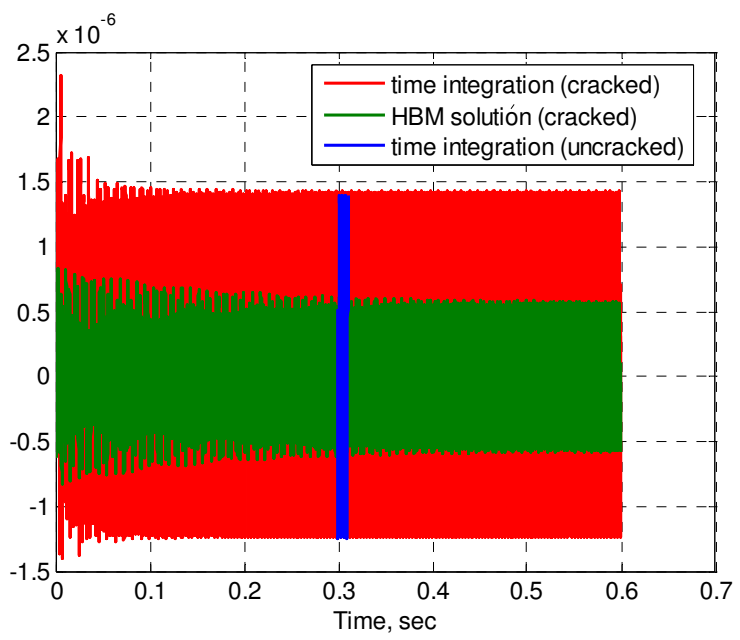

c
In figure 12 the solutions of the system motion equation using both harmonic balance and direct time integration approach are presented. They confirm that the harmonic balance method is more effective in terms of time, because it is enough to have the time interval equal to the excitation period. For the direct integration approach, solution time interval is much bigger.

It should also be stressed that, as was said before, the response period is not always equal to the period of external excitation. In this case, the results of the harmonic balance method will be different from time integration results. Response period multiplication can also appear.

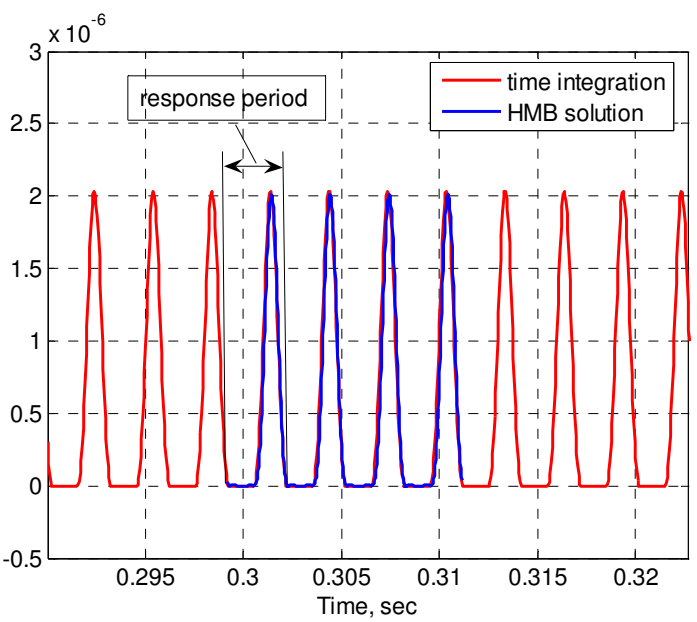

$b$

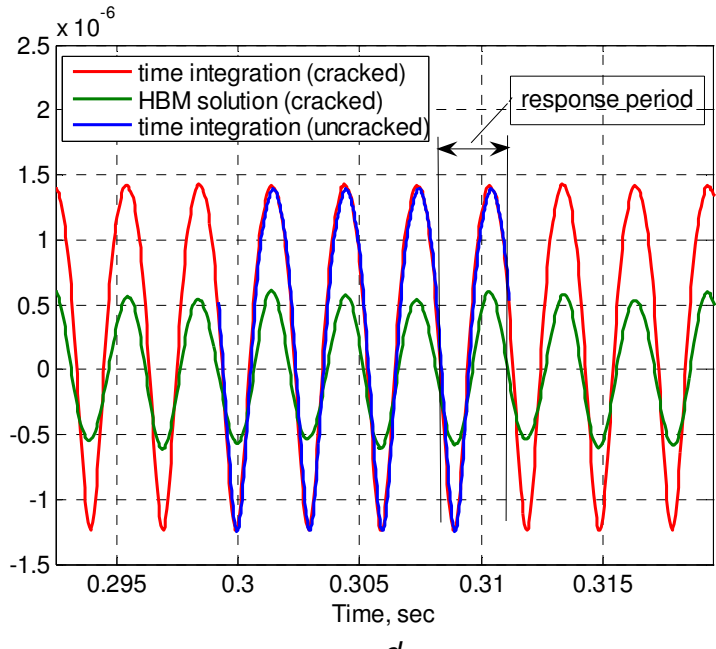

$d$

Fig 12. Non-linear solution by HB method and direct integration approach: $a-$ at the crack point, $b$ - at the crack point (zoom), $c$ - at the tip point, $d$ - at the tip point (zoom)

\section{Frequency response function of the non- linear cracked blade model}

The construction of the frequency response function of the cracked blade model was performed for the same cases as the simulation of system response in the time domain. The cracked blade model is presented in figure 1 $b$ and crack location schemas are presented in figure 4 . Comparison of the frequency response was fulfilled by linear cracked, non-linear cracked and linear uncracked blade models. The frequency range covered the first three eigenmodes: the first and second bending modes and first torsion mode. As we did not know exactly the eigenfrequencies of the cracked blade model because of crack induced non-linearity, frequency discretisation was done around eigenmode frequencies of the linear cracked and uncracked models. Because of this, the resonances picks of the non-linear model sometimes appear to be not smooth and with amplitude a bit lower than it should be. 
In the previous chapter we dealt with system solution, in particular frequency point (in our case, 3500 $\mathrm{rad} / \mathrm{sec}$ ), having initialized the non-linear procedure by linear approximation. Such an approach is suitable in the frequency diapasons situated far from resonance, where the difference between linear and non-linear solutions is barely visible, whereas in the resonance area such initialization can lead to a longer convergence process or even to its lack of convergence. To tackle this problem, as initialization for a particular frequency point the non-

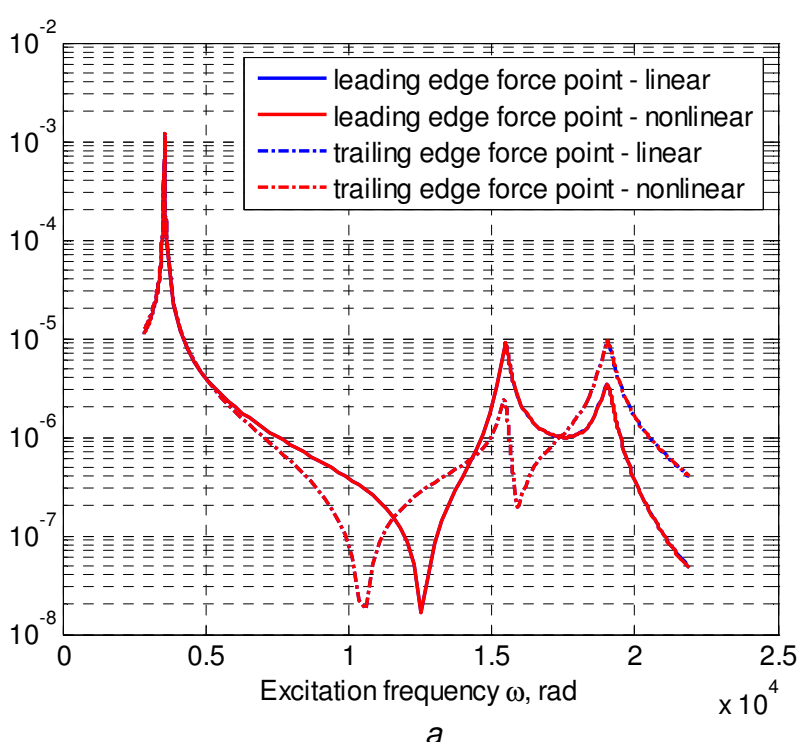

a

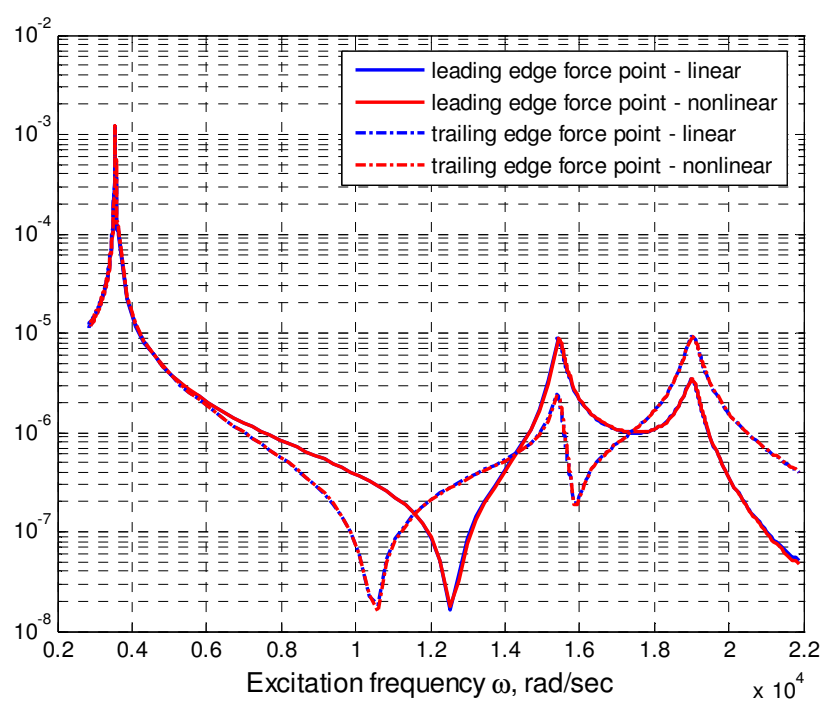

$c$ linear solution obtained at the previous point was used . Another measure for dealing with solution nonconvergence involves frequency continuation approaches in which the next frequency point is searched by prediction on the base of a polynomial approximation (Von Groll et al. 2001).

In a way that is analogous to the solution of the problem in the time domain (section 4), we will start by examining the smallest crack size of $2 \mathrm{~mm}$ (Fig 13).

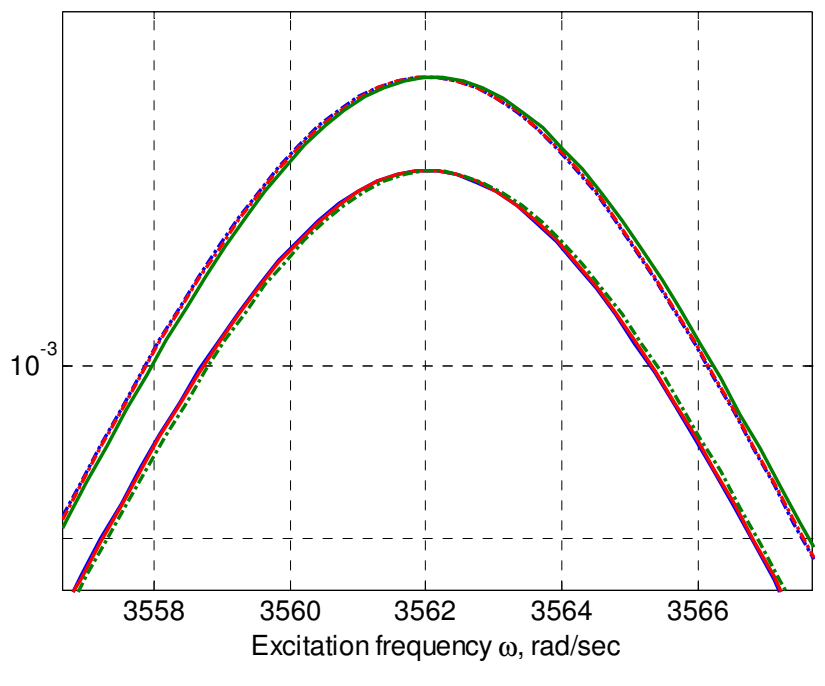

$b$

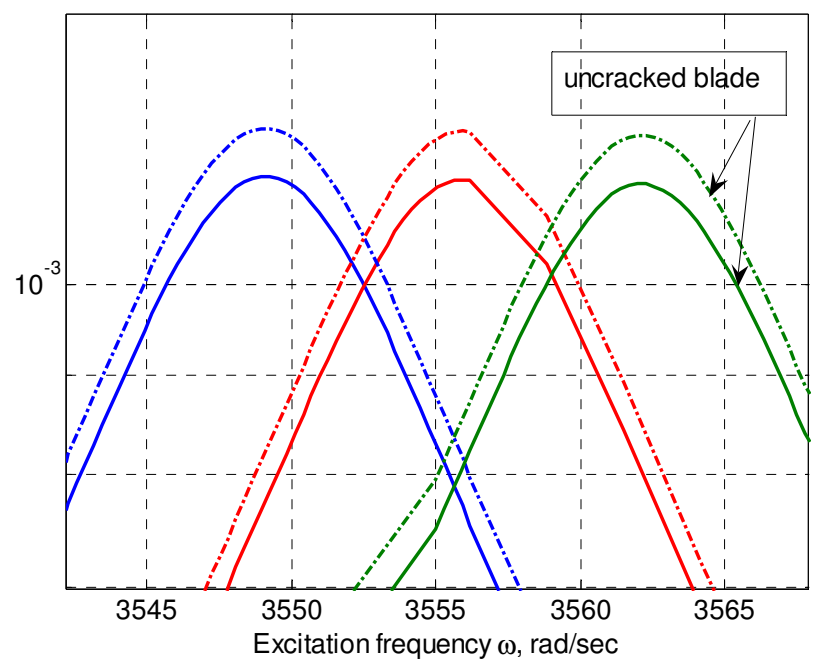

$d$

Fig 13. Cracked blade frequency response function (crack size $2 \mathrm{~mm}$ ): $a$ - trailing edge crack, $b$ - trailing edge crack (zoom around first eigenfrequency), $c$ - leading edge crack, $d$ - leading edge crack (zoom around first eigenfrequency)

Frequency response for a cracked blade with a crack of $2 \mathrm{~mm}$ reflects said in the previous chapter: such crack size can have visible influence only for leading crack case. When crack is located on trailing edge its effect became more or less observable for fourth higher order eigenmodes.

The results demonstrate that a crack of this size can be considered the minimum able to be identified. The ability to detect cracks could possibly be weaker when a cracked blade is considered within the frameworks of the bladed disk model.

Next, the case of the 4-mm crack will be simulated (Fig 14). Phase change at force application points will also be shown (Fig 15). 


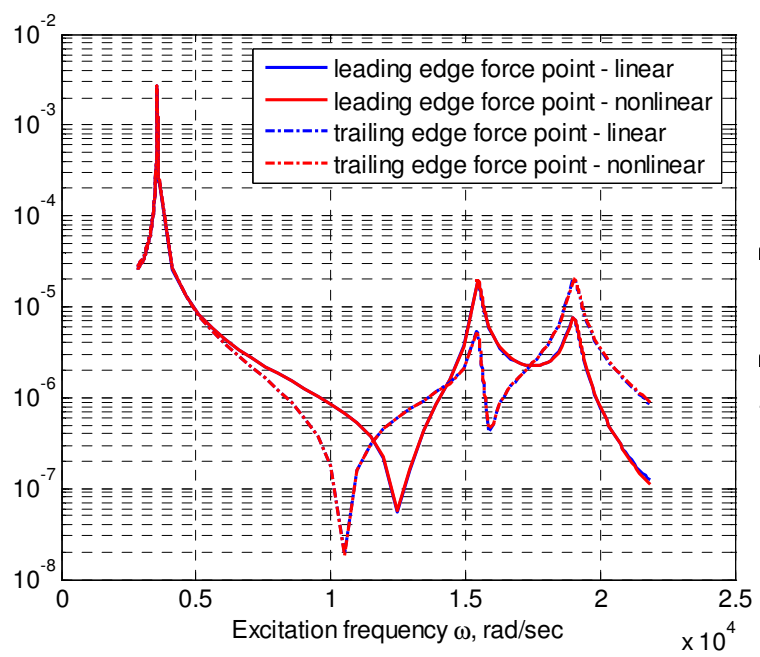

a

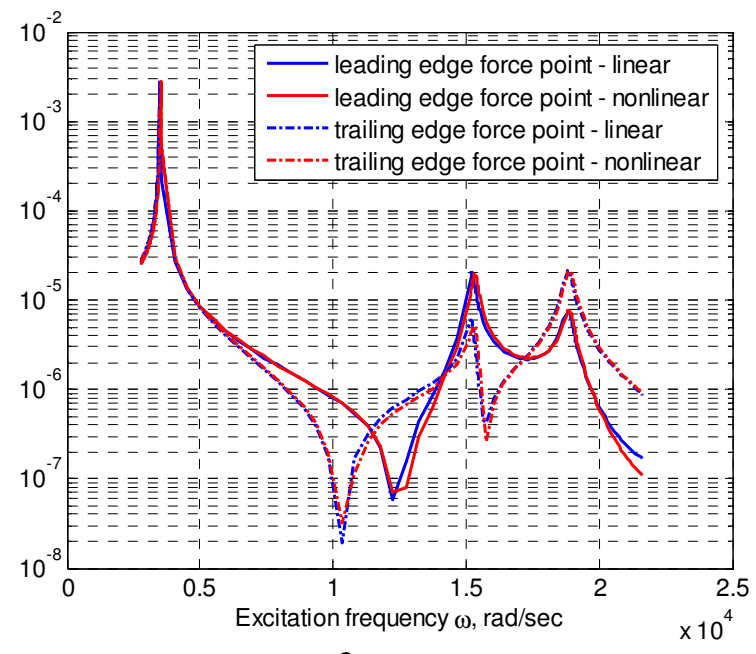

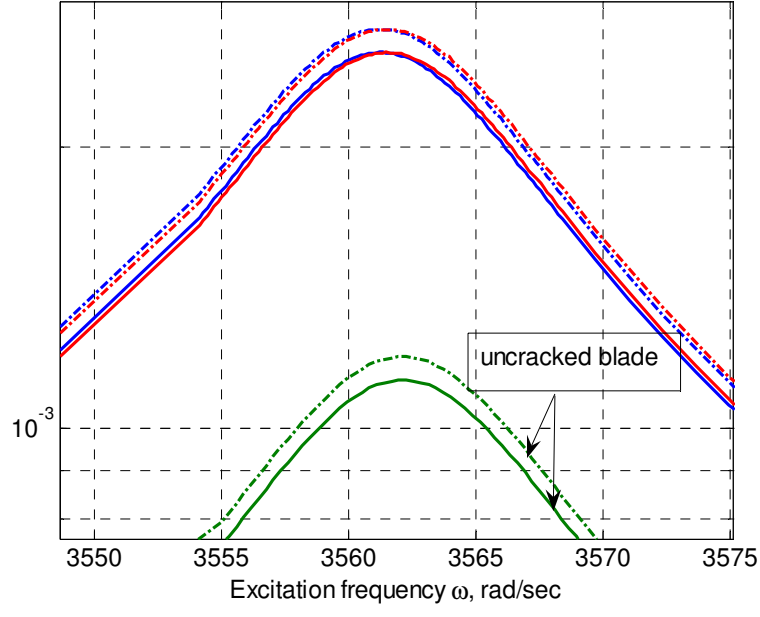

b

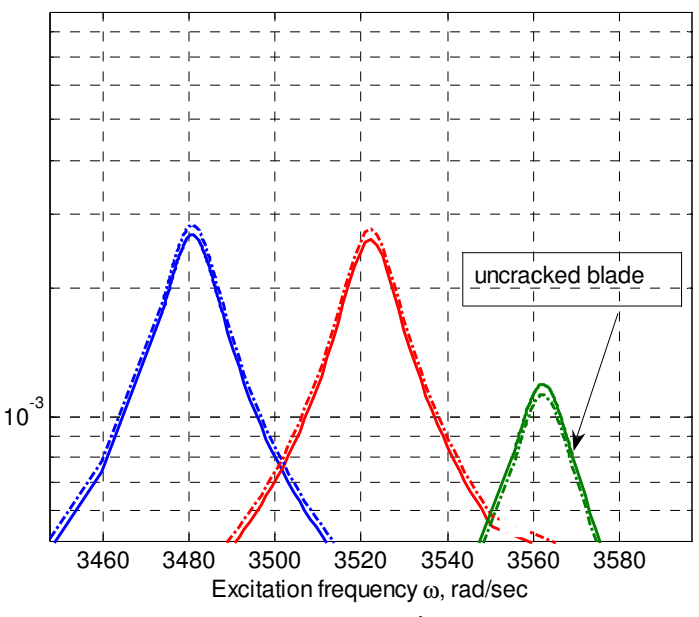

d

Fig 14. Cracked blade frequency response function (crack size $4 \mathrm{~mm}$ ): ): $a$-trailing edge crack, $b$ - trailing edge crack (zoom around first eigenfrequency), $c$ - leading edge crack,

$d$ - leading edge crack (zoom around fourth eigenfrequency)

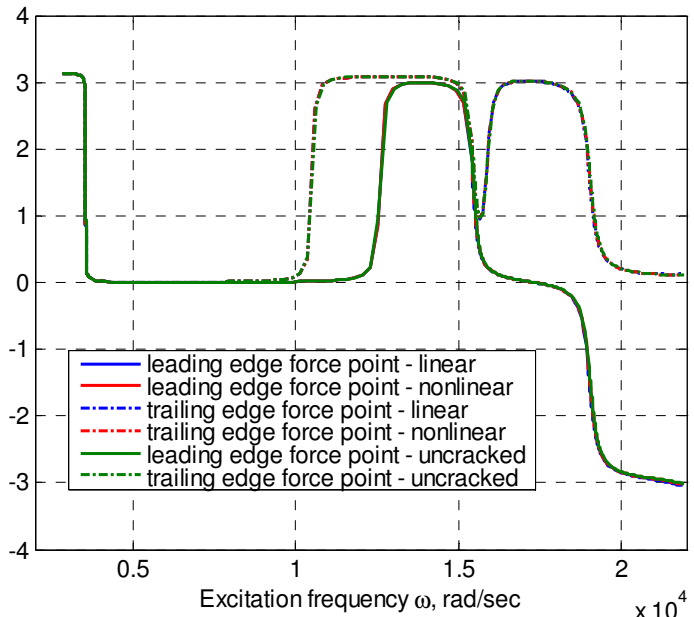

a

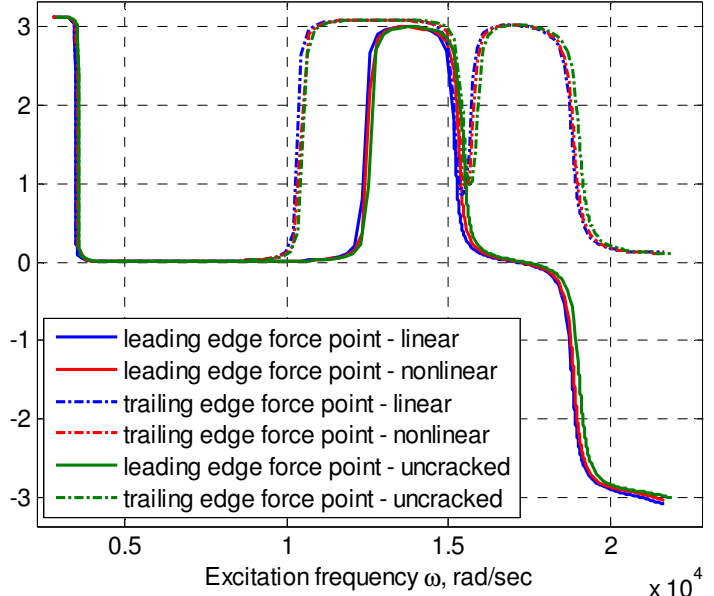

$b$

Fig 15. Cracked blade response phase change (crack size $4 \mathrm{~mm}$ ): $a$ - trailing edge crack, $b$ - leading edge crack

Looking at cracked blade response phase change, we can see sufficient difference between the cracked and uncracked solutions (Fig 15). It is only notable in the case of the $4 \mathrm{~mm}$ crack, and with a smaller value the difference is almost unobservable.
In addition to crack locations on the trailing or leading edges, the case of symmetric crack is shown in figures 16-18. The location of cracks is presented in figure $4 c$. The response of the system to such cracks is mostly influenced by cracks located on the leading edge. 


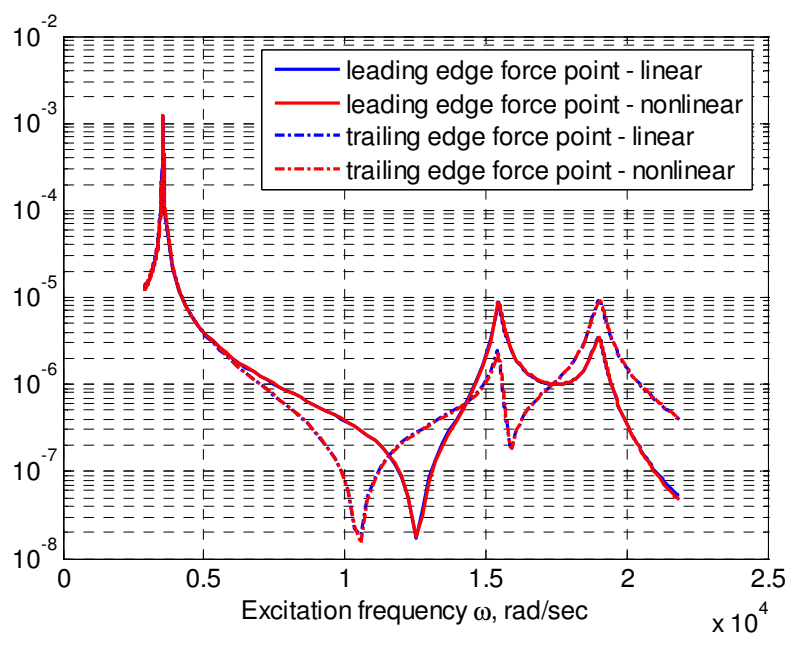

a

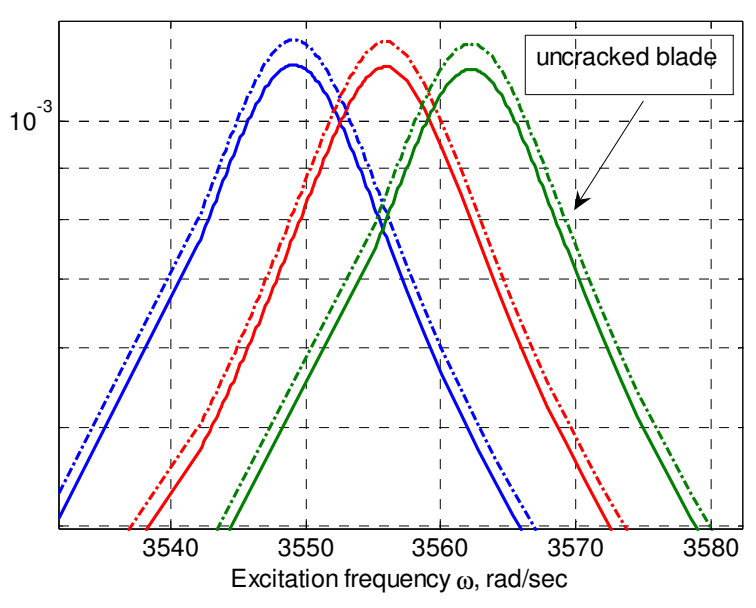

$b$

Fig 16. Cracked blade frequency response function (symmetric crack, crack size $2 \mathrm{~mm}$ ): $a$ - full frequency range, $b$ - zoom around first eigenfrequency

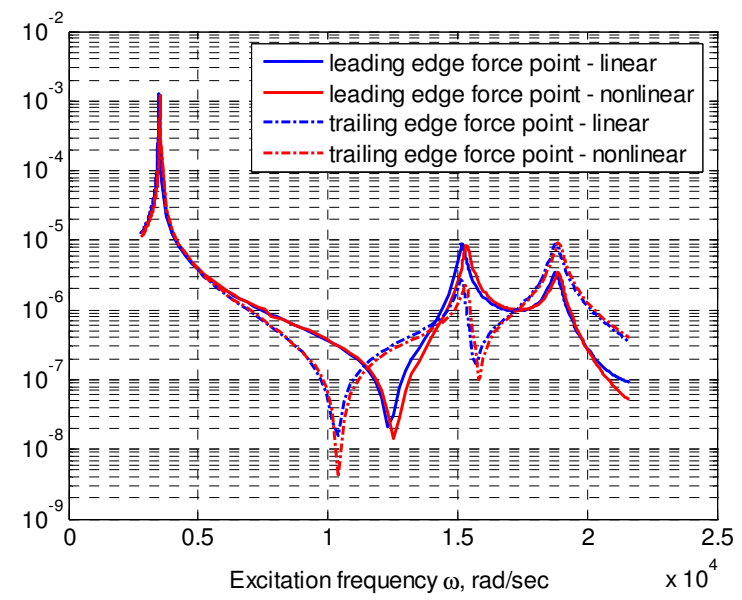

a

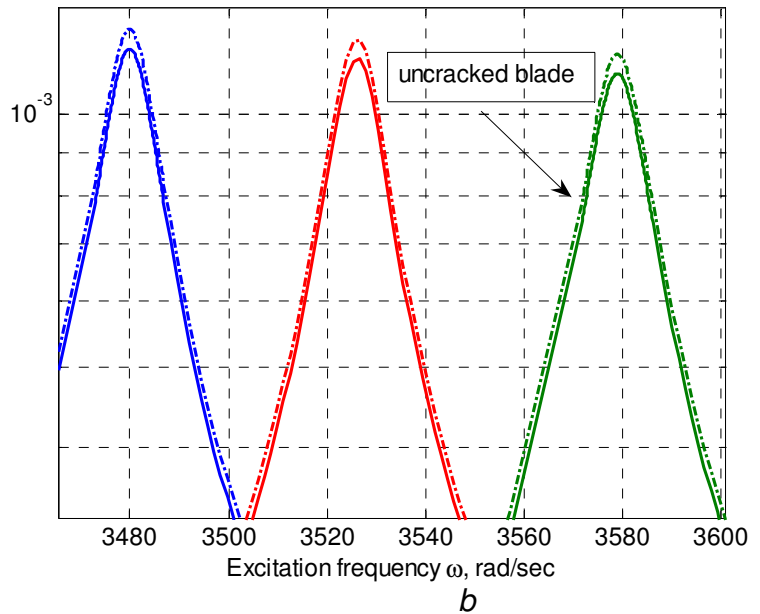

$b$

Fig 17. Cracked blade frequency response function (symmetric crack, crack size $4 \mathrm{~mm}$ ): a - full frequency range, $\mathrm{b}-$ zoom around first eigenfrequency

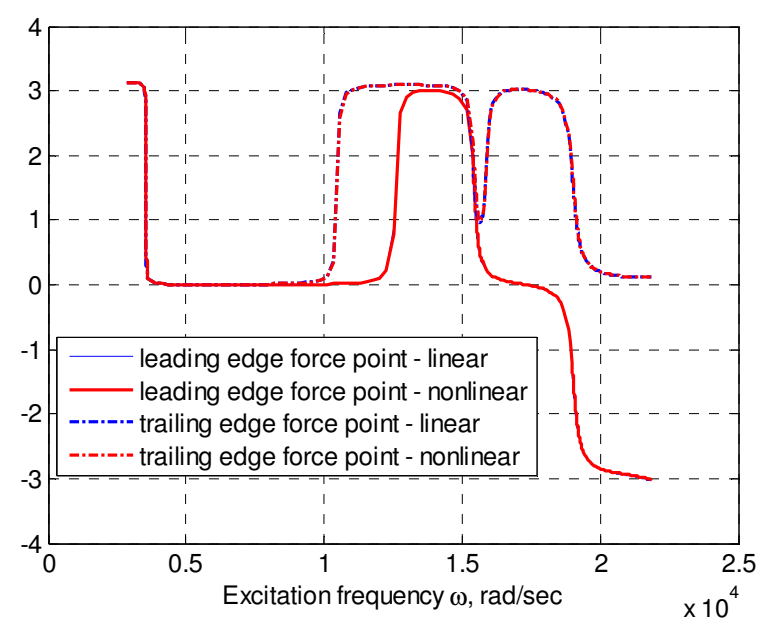

a

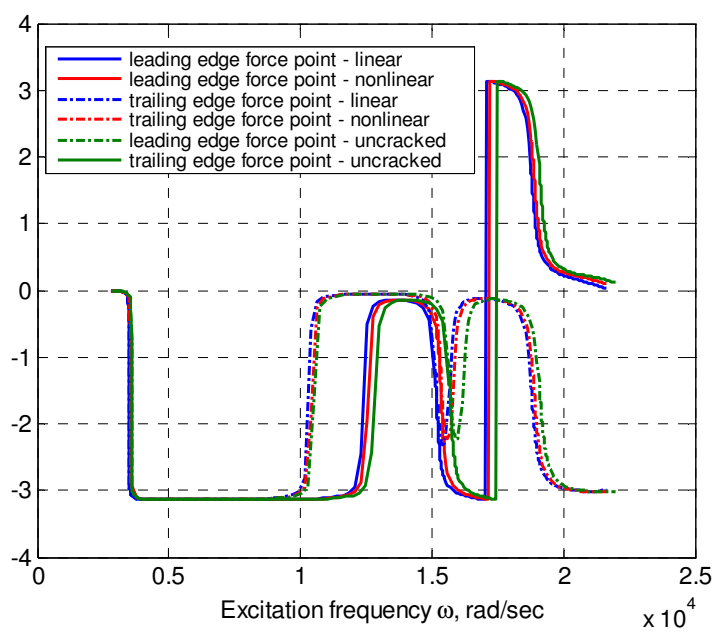

$b$

Fig 18. Cracked blade response phase change (symmetric crack): $a$ - crack size $2 \mathrm{~mm}, b$ - crack size $2 \mathrm{~mm}$

From the simulation of the cracked blade frequency response supposing the presence of two symmetrically located cracks, we can derive that this case is more severe for the structure. Even at the presence of 2-mm cracks, their influence became evident and is mostly due to the effect of leading edge crack.

From all simulation cases, we can see that the response of the non-linear cracked blade model has an 
intermediate location between the responses of the linear cracked and uncracked blade models.

\section{Effect of centrifugal forces on non- linearity of cracked blade}

Determining the effect of centrifugal forces is quite a challenging task in the attempt to represent accurately all physical phenomena associated with bladed disc dynamics and to improve the non-linear cracked blade model used in forced response predictions. The significance of incorporating the effect of centrifugal forces in the analysis of cracked blades is demonstrated by their influence on the vibration response of the nonlinear cracked blade model. Some numerical examples serve to confirm the theoretical predictions and successful implementation that will increase confidence in the proposed model.

By definition, an inertial reference frame is a coordinate system defined by non-accelerated motion with constant direction and velocity. An approximation of the frame, in which Newton's laws of motion are valid, is a system with fixed coordinates in the rotating earth (Goldstein 1980). A non-inertial reference frame is a coordinate system that is accelerating: changing its direction and/or velocity. Many turbomechanical components, such as bladed discs, are exposed to the effects of forces resulting from rotation and acting on the system in a rotating (non-inertial) reference frame.

In contrast to rotordynamics, the effects of the Coriolis forces are usually excluded from the vibration analysis of bladed discs because it is assumed that they

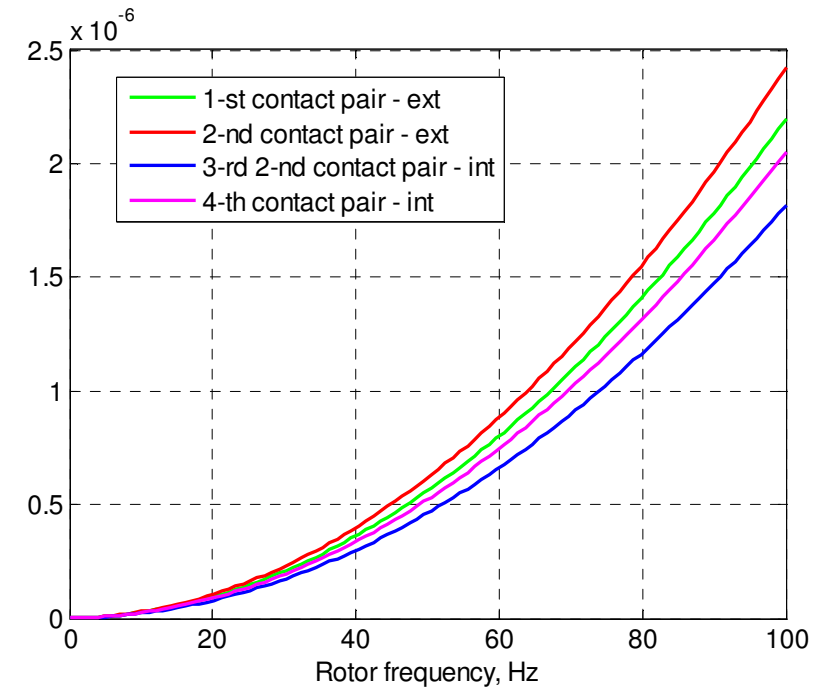

a are of negligible value. In the case of bladed disk vibration, this fact is commonly attributed to the belief that Coriolis forces usually do not change natural frequencies, mode shapes, or other dynamic properties of bladed disks sufficiently. It should be noted that for all mode shapes except those with dominant 0 or 1 nodal diameter components, all bending moments are balanced, so that there is no significant interactive energy transfer between the bladed disk and the supporting shaft. This is the feature that generally enables the analysis of the bladed disk vibration to be made in isolation from the supporting structure.

In our case, the investigation of the effect of centrifugal forces will be performed in following manner. As was mentioned before, the centrifugal force acts in the radial direction during the rotation of a bladed disk. In the uncoupled cracked blade model, centrifugal force will form a gap between the sides of a crack. This gap can be accepted as the initial opening of the crack during its breathing process. The initial value of the gap will depend on:

- crack size;

- crack location (trailing edge, leading edge);

- amplitude of external loading;

- rotation frequency of rotor.

In figure 19, the results of the simulation of crack initial opening are presented for different frequencies of rotation. In order to perform this task, the finite-elements model of the cracked blade used for the application of the harmonic balance method was used The solution is shown for all contact pairs, supposing the presence of a 4$\mathrm{mm}$ crack on both the trailing and leading edges.

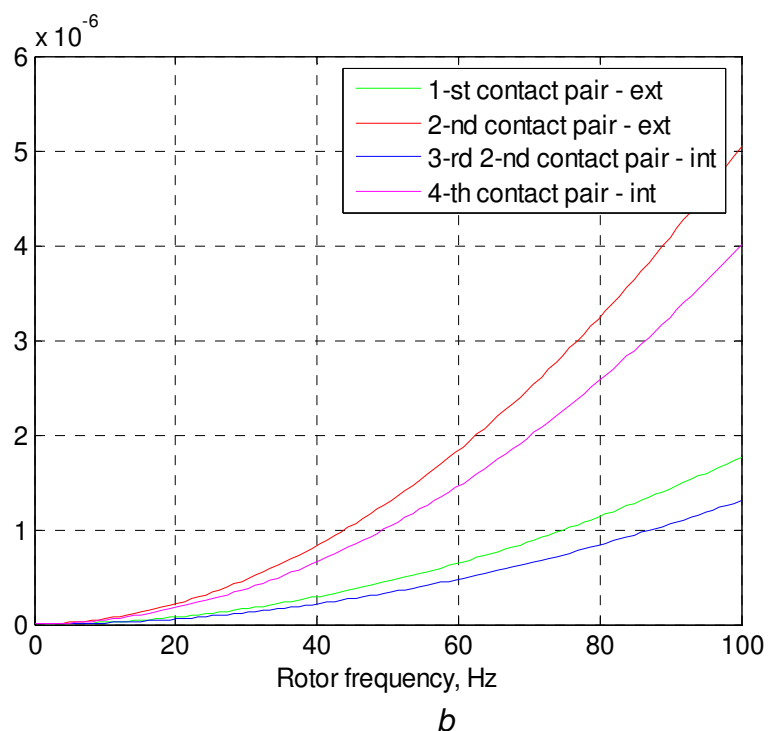

$b$

Fig 19. Initial crack opening due to the effect of centrifugal forces: $a$ - trailing edge crack, $b$ - leading edge crack

The data from figure 19 will then be used to calculate the dynamic response of cracked blades using the harmonic balance method. Initial gap values are substituted in the equation of contact force approximation (4). Then the harmonic balance procedure is solved, taking into account a gap. We present a simulation of cracked blade response at different gap values with fixed excitation frequency (Figs 20-22). In this case, we will change the engine order of excitation in order to provide constant excitation frequency, change gap value, and at the same time, rotor frequency $\Omega$.

For all simulation cases, excitation frequency of $3500 \mathrm{rad} / \mathrm{sec}$ was maintained constant while varying the engine order of excitation and rotor frequency. 

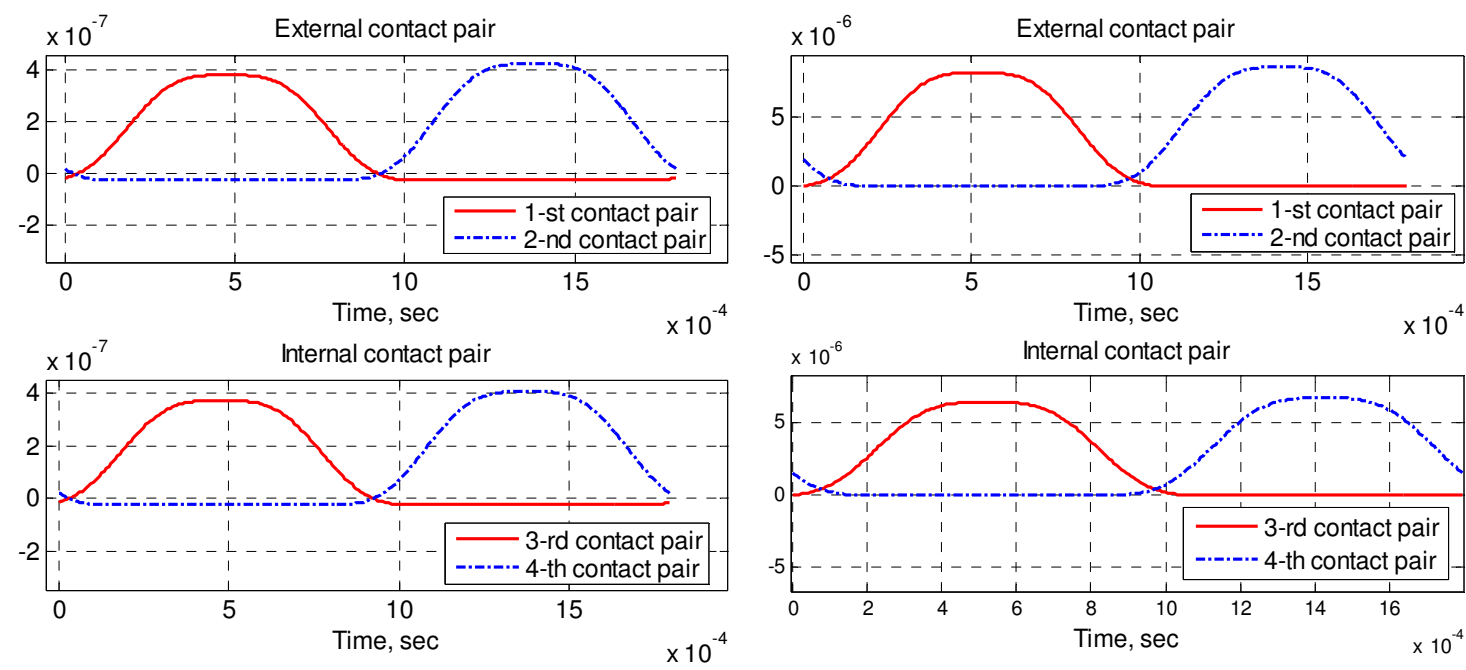

a

$b$

Fig 20. Non-linear solution at initial crack opening $(\Omega=10 \mathrm{~Hz})$ : $a$ - trailing edge crack, $b$ - leading edge crack
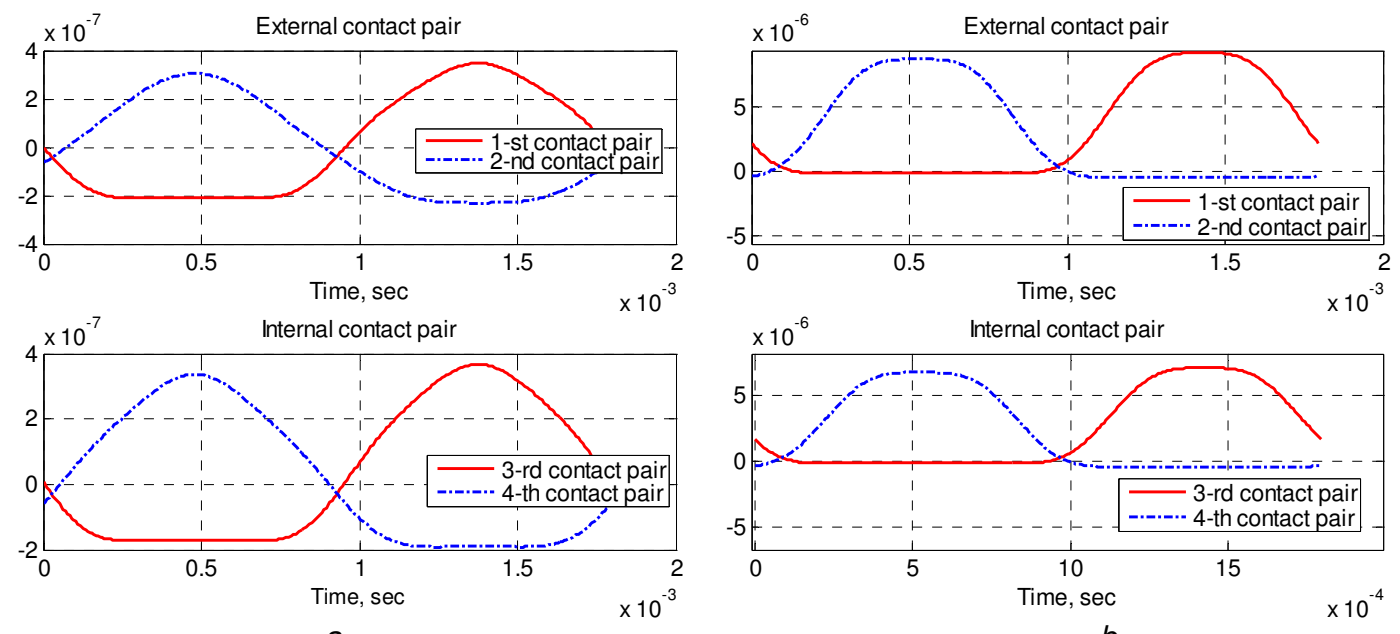

$b$

Fig 21. Non-linear solution at initial crack opening $(\Omega=30 \mathrm{~Hz}): a$ - trailing edge crack, $b$ - leading edge crack
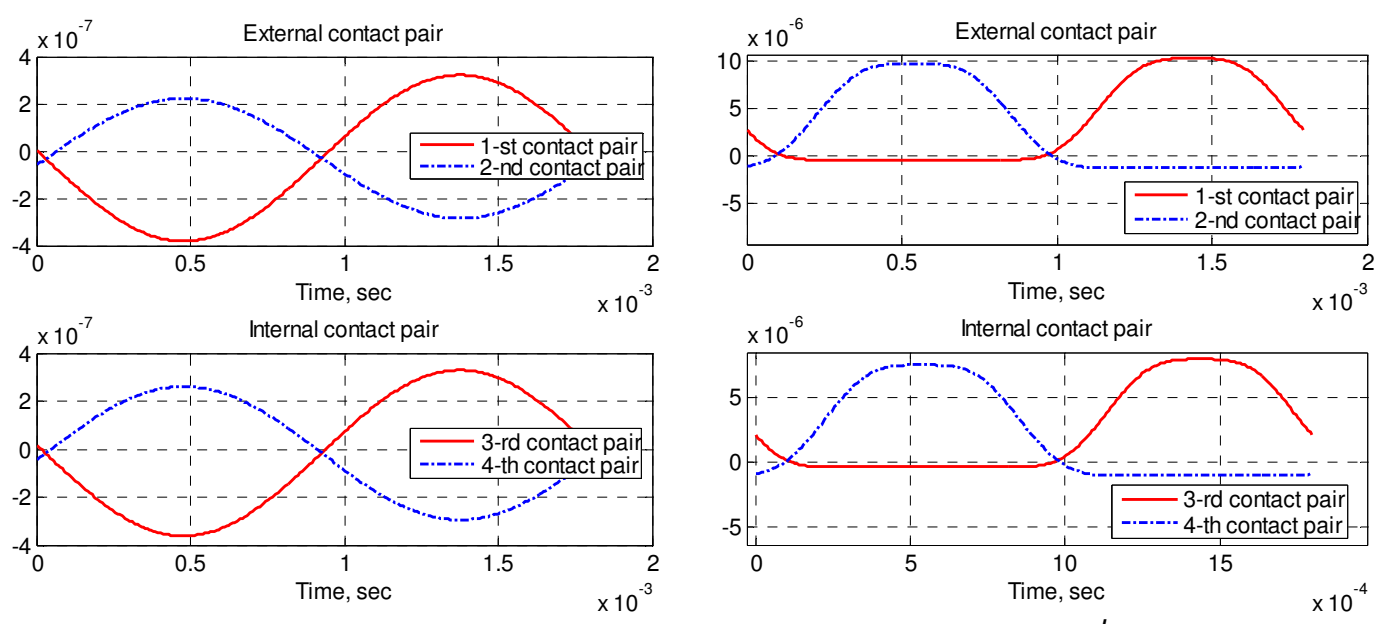

a

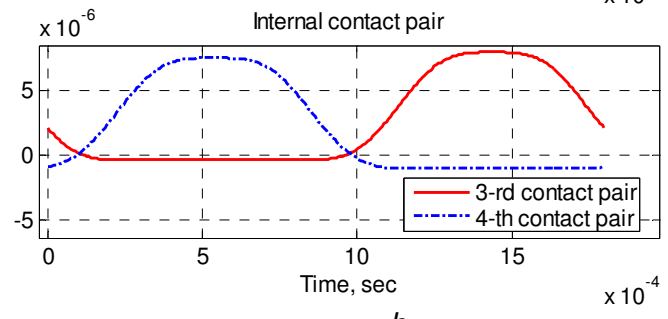

$b$

Fig 22. Non-linear solution at initial crack opening $(\Omega=50 \mathrm{~Hz})$ : $a$ - trailing edge crack, $b$ - leading edge crack

Main conclusion, which can be made after analyzing the results presented in figures 20-22, is that taking into account centrifugal forces effect leads to useless nonlinear formulation of the cracked blade dynamic behaviour. Such a phenomenon is observed with the increase in rotor frequency. It becomes visible earlier for a trailing edge crack due to its smaller opening level in comparison with initial crack opening. At the same time, for a crack on the leading edge, crack-induced nonlinearity should be taken into account at all rotor frequencies. 
The simulation performed above is very important in the point of view of computation time expenses because it allows using a cracked blade linear model in some range of rotor frequency change.

\section{Conclusions}

The presented study was dedicated to the presentation of a cracked blade non-linear model and its solution by the application of the harmonic balance method.

The cracked blade non-linear dynamical model was created using the harmonic balance method in conjunction with the contact approach of the simulation of the crack breathing process. This model allows us to describe cracked behaviour at any loading amplitude and excitation frequency. The influence of centrifugal forces was also simulated. It was concluded that the initial opening of a crack due these forces leads to the uselessness of crack non-linear representation.

In general, some factors were derived from the analyses when compared with uncracked blades

- eigenmode frequency reduction;

- increase in tip response amplitude.

It should be noted that the frequency response of cracked blades, taking into account non-linearity, stands in an intermediate position between the linear cracked blade response and the response of an uncracked blade. This fact can cause the deterioration of cracked blade detection, especially if the non-linear model is included in the global bladed disk dynamic model.

Moreover, additional factors affecting the ability to detect the presence of cracks must be included in the further development of the bladed disk model. The most harmful is blade mistuning, bringing uncertainty to the dynamic analysis of the system and making cracked blade behaviour similar to mistuned blades.

\section{References}

Cheng, S.; Wu, X.; Wallace, W. et al. 1999. Vibrational response of a beam with a breathing crack. Journal of Sound and Vibration, 225: 201208.

Chengwu, D.; Rajendra, S. 2007. Dynamic analysis of preload non-linearity in a mechanical oscillator. Journal of Sound and Vibration, 301: 963-978.

Craig, R.; Bampton, M. 1968. Coupling of substructures for dynamic analysis. AIAA Journal, 6(7): 1313-1319.

Goldstein, H. 1980. Classical Mechanics. Addison Wesley Series in Physics Second Edition.

Von Groll, G.; Ewins, D. 2001. The harmonic balance method with arc-length continuation in rotor/stator contact problems. Journal of Sound and Vibration, 241(2): 221-233.

Kucher, O.; Kharyton, V.; Laine, J.-P. et al. 2007. Harmonic balance method implementation for crack breathing process simulation. Aerospace technique and technology, 8(44): 150-156.

Laine, J.-P.; Kharyton, V. 2006. Cracked structure response on external harmonic excitation. Aerospace technique and technology, 61: 1057-1074.

Liu, L.; Thomas, J.P.; Dowell, E.H. 2006. A comparison of classical and high dimensional harmonic balance approaches for a Duffing oscillator. Journal of Computational Physics, 215: 298-320.

\section{MENTELĖS SU İTRŪKIMU NETIESINĖ DINAMIKOS ANALIZĖ}

M. Kulyk, O. Kucher, V. Kharyton, J.-P. Laine, F. Thouverez

S a n trauka

Mentelès su įtrūkimu netiesinė dinamikos analizė atlikta įvertinant įtrūkimo kraštų kontaktinę sąveiką. Netiesinis uždavinys sprendžiamas harmoninės analizès metodu. Tokio metodo rezultatų tinkamumas ir efektyvumas demonstruojamas lyginant su sistemų dinaminių lygčių skaitinio sprendimo rezultatais. Sprendžiamo uždavinio eilè mažinama kraštų fiksavimo metodas. Šiuo atveju buvo laikoma, kad plyšys suformuoja ribą tarp dviejų konstrukcijos daliu ir plyšio ribu kitimo aprašymui naudojamos santykinès koordinatès. Buvo ištirta išcentriniu jègu itaka netiesiniam formulavimui, priklausomai nuo plyšio padèties ir kampinio greičio.

Reikšminiai žodžiai: mentelè su plyšiu, kontaktas, harmoninio balanso metodas, amplitudès - dažnio charakteristika, savasis dažnis. 